\title{
Undiluted or extended storage of ram epididymal spermatozoa as alternatives to refrigerating the whole epididymes
}

\author{
ג. Tamayo-Canul ${ }^{\mathrm{a}, \mathrm{b}}$, M. Alvarez ${ }^{\mathrm{a}, \mathrm{b}}$, E. López-Urueña ${ }^{\mathrm{a}, \mathrm{b}}$, M. Nicolas $^{\mathrm{a}, \mathrm{b}}$, F. Martinez-Pastor ${ }^{\mathrm{a}, \mathrm{c}}$, \\ E. Anel ${ }^{\mathrm{a}, \mathrm{b}}, \mathrm{L}$. Anel ${ }^{\mathrm{a}, \mathrm{b}}$, P. de Paz ${ }^{\mathrm{a}, \mathrm{c}, *}$ \\ a ITRA-ULE, INDEGSAL, University of León, 24071 León, Spain \\ b Animal Reproduction and Obstetrics, University of León, 24071 León, Spain \\ c Molecular Biology, University of León, 24071 León, Spain
}

\section{A R T I C L E I N F O}

\section{Article history:}

Received 1 November 2010

Received in revised form 11 April 2011

Accepted 20 April 2011

Available online $\mathrm{xxx}$

\section{Keywords:}

Ram

Epididymis

Refrigerated storage

Osmolality

仓xtender

Sperm quality

\begin{abstract}
A B S T R A C T
The effect of storage procedure at $5{ }^{\circ} \mathrm{C}$ on the quality of ram spermatozoa from the cauda epididymis was analyzed. Two strategies were tested at $0,24,48$ and $72 \mathrm{~h}$ post-mortem: (1) spermatozoa held in the epididymal fluid and stored either in the cauda epididymis (InEPID) or in vitro (Ex-EPID), (2) epididymal spermatozoa extended in three media at 320, 370 and $420 \mathrm{mOsm} / \mathrm{kg}$ (D320, D370, D420). Analyzed parameters were: osmolality, pH, motility, acrosomal status and viability. In experiment 1 , osmolality of the An-EPID samples, but not in Ex-EPID, increased with post-mortem time. Motility of In-EPID spermatozoa in samples, after $24 \mathrm{~h}$ post-mortem, was higher compared to the Ex-EPID samples, although differences decreased at 48 and $72 \mathrm{~h}$. In experiment 2, total (TM) and progressive motility (PM) were not significantly affected by storage time for D320 and In-EPID samples. However, the motility of D370 and D420 samples significantly decreased with time. TM and PM of D320 were significantly higher than D370 and D420 at $72 \mathrm{~h}$. At $24 \mathrm{~h}$, sperm viability was higher for InEPID $(80.7 \pm 3.4 \%)$ than for the extended samples ( $44.8 \pm 2.9 \%, 37.7 \pm 3.9 \%$ and $48.6 \pm 6.0 \%$ for D320, D370 and D420, respectively), which also decreased faster with time. At $24 \mathrm{~h}$, the percentage of damaged acrosomes was low and similar for the four methods of storage, but damaged acrosomes increased with time for D320 and D370. Storing the spermatozoa in the epididymis is a good strategy for maintaining sperm quality in ram, at least for $48 \mathrm{~h}$. The D320 extender preserve motility of epididymal spermatozoa but does not protect the status of the acrosome.
\end{abstract}

(c) 2011 Published by Elsevier B.V.

\section{Introduction}

In the last decade the conservation of rare breeds of domesticated species has been very difficult and many of them have disappeared or are going to become extinct (Canali, 2006). This loss of biodiversity has been due to a poor management policy of genetic resources. In Spain, there is a wide range of animal genetic resources due

Q1 * Corresponding author at: Molecular Biology, University of León, 24071 León, Spain. TÂ.: +34 9872911320; fax: +34 913474014.

E-mail address: ppazc@unileon.es (P. de Paz). to its specific geographical and climatic characteristics. These resources are threatened by the introduction of alien breeds with high production rates, and as an example we can cite the 34 sheep breeds officially declared endangered. This situation has motivated the implementation of a National Programme for conservation, improvement and promotion of livestock breeds (Royal Decree 2129/2008). This programme recommended establishing a germplasm bank for certain sheep breeds with increased risk of losses of genetic variability. This bank would ideally contain germplasm systematically collected from living animals. However, genetically valuable animals may die unexpectedly, calling for a methodology to collect their germplasm 

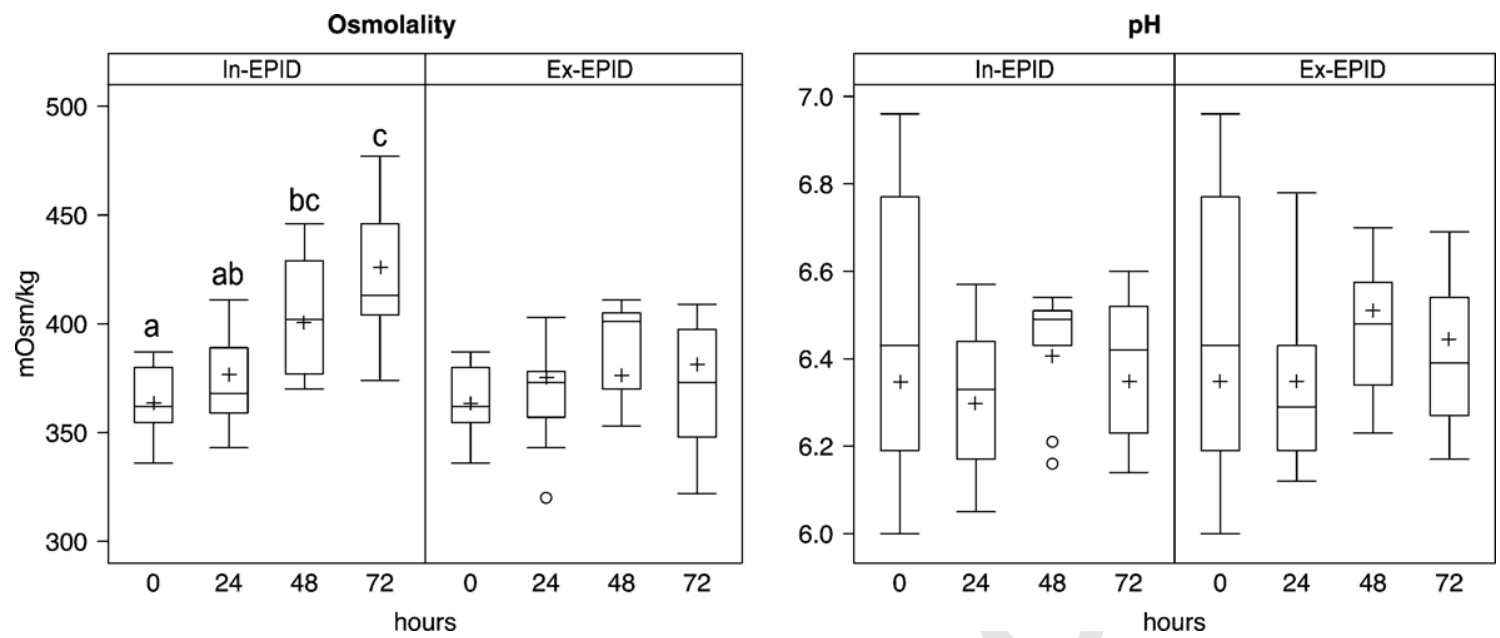

Fig. 1. Osmolality and pH of the epididymal samples, Intra-epididymal (In-EPID) and Extra-epididymal undiluted (Ex-EPID), at each sampling time (0, 24, 48 and $72 \mathrm{~h}$ ). Lower and upper limits of the boxes indicate the first and third quartiles, respectively, and the horizontal line inside indicates the median. The whiskers reach the maximum and the minimum values of the range. The mean is shown with a cross. Within each treatment, sampling times not sharing letters differ significantly $(P<0.05)$.

post-mortem. In that event, the post-mortem collection of epididymal spermatozoa allows the conservation of valuable genetic material that would otherwise be lost (Saragusty et al., 2006). Epididymal spermatozoa provide a sufficient quantity of viable spermatozoa to be used to fertilize oocytes with the resulting zygotes being able to develop into live young (Songsasen et al., 1998; Sankai et al., 2001; Soler et al., 2003a; Martins et al., 2009).

However, sperm in the epididymis are viable only for a certain period of time and then degenerate rapidly (Hishinuma et al., 2003; Kaabi et al., 2003; Soler et al., 2003b; Yu and Leibo, 2002). Previous studies in several species have indicated that storage of epididymides at $5{ }^{\circ} \mathrm{C}$ may be an appropriate way to maintain sperm motility and fertilizing capacity for several days (mice: An et al., 1999; cat: Ganan et al., 2009; boar: Kikuchi et al., 1998; mouse: Kishikawa et al., 1999; red deer: Martinez-Pastor et al., 2005a; bull: Martins et al., 2009; dog: Yu and Leibo, 2002).

Kaabi et al. (2003) preserved ram epididymides at $5{ }^{\circ} \mathrm{C}$, finding good sperm viability until $48 \mathrm{~h}$ post-mortem, although their in vitro fertility potential declined significantly after $24 \mathrm{~h}$. Similarly, Martinez-Pastor et al. (2005b) found that deer sperm quality obtained from the epididymis was mostly maintained for the first two days.

In studies examining the conservation of epididymal sperm, the epididymides are usually transported to the laboratory from the site of slaughter at $5^{\circ} \mathrm{C}$. In this period, alterations in the physical environment of the epididymal sperm may cause a loss in sperm quality. Histological examination of mouse epididymides revealed that distinct degenerative changes did not occur until $12 \mathrm{~h}$ postmortem (Songsasen et al., 1998) when the epitheliâl cells became pyknotic and released their intracellular contents into the lumen of the epididymides. By $24 \mathrm{~h}$ postmortem, the structure of the epididymal tubule appeared to be breaking down. Martinez-Pastor et al. (2005b) found that osmolality of the epididymal media in red deer increased with postmortem time.

If the epididymis changes its structure after $12 \mathrm{~h}$ postmortem, it is possible that the epididymal microenvironment then begins to be harmful to sperm. We hypothesized that extracting the spermatozoa in the field, refrigerating them either undiluted or extended, and keeping them so for several days post-mortem might represent an advantage, comparing to the traditional methodology of storing the whole epididymes. Therefore, these could be alternative strategies for maintaining the quality of postmortem samples, when immediate cryopreservation is not possible (Sankai et al., 2001; Fernandez-Santos et al., 2009).

The objective of this study was to analyse the effect of storage at $5{ }^{\circ} \mathrm{C}$ on the quality of ram epididymal sperm by: (1) evaluation of spermatozoa held in the epididymal fluid and stored either in the organ or in vitro, (2) analysis of epididymal spermatozoa extended in the same medium at different osmolalities.

\section{Materials and methods}

\subsection{Reagents}

All the products were obtained from Sigma (Madrid, Spain), except for the SYBR-14 (LIVE/DEAD Sperm Viability Kit) and YO-PRO-1 fluorescence probes, which were acquired from Invitrogen (Barcelona, Spain).

\subsection{Animal and sample collection}

Testes were collected from fifteen rams (Churra breed) after slaughter, and transported in a refrigerated cooler $\left(5^{\circ} \mathrm{C}\right)$ to the laboratory (University of León) within the first $2-4 \mathrm{~h}$ post-mortem. In a cold room, the caudae epididymides were isolated, the superficial vessels were cut to reduce blood contamination and the organ was kept at $5{ }^{\circ} \mathrm{C}$. 


\subsubsection{Experimental design}

Two experiments were carried out. In experiment 1 , we compared sperm quality, osmolality and $\mathrm{pH}$ among intraepididymal and undiluted extra-epididymal storage $(9+9$ epididymides). In experiment 2 , we tested the effect of dilution of the epididymal spermatozoa in three extenders of increasing osmolality (320, 370 and $420 \mathrm{mOsm} / \mathrm{kg}$ ), using intra-epididymal stored samples as the control group ( 6 epididymes for control and 6 for dilution in the three extenders). These three osmolalities were chosen according to previous experiment and represent a hypo-osmotic, iso-osmotic and hyper-osmotic medium, respectively, comparing to the physiological osmolality of the caudal epididymal fluid (experiment 1 : the mean value is 365 (isotonic value), with a range of distribution of 355 (25th percentile) to 381 ( 75 th percentile)).

\subsubsection{Sample collection}

In each cauda epididymes, two symmetrical parts were isolated by a clamp. Experiment 1: one part was maintained without manipulation and the sperm mass was obtained at the different sampling times $(0,24,48$ and $72 \mathrm{~h})$ performing sequential cuts in defined areas of the surface with a scalpel (Intra epididymal sample, In-EPID). The other portion was processed by cuts to obtain the total sperm mass in a glass tube where it was kept undiluted (Extra epididymal sample, Ex-EPID) and samples were obtained sequentially in different time periods (24, 48 and $72 \mathrm{~h})$.

Experiment 2: one part of each cauda was kept as the control (In-EPID) and was manipulated as described in the previous experiment. In the other portion, the total sperm mass was obtained by cuts and this sample was aliquoted and diluted with the same volume of each TTF media (TES-Tris-fructose, pH 7.2, 20\% egg yolk and 8\% glycerol) with different osmolalities (320, 370 and $420 \mathrm{mOsm} / \mathrm{kg}$, obtained by varying fructose). These diluted aliquots were coded as D320, D370, D420, respectively. Each aliquot was sampled sequentially for analysis each $24 \mathrm{~h}$ (24, 48 and $72 \mathrm{~h}$ ). TTF media containing glycerol, since the epididymal spermatozoa were prepared for freezing.

Between sampling times, the portions of epididymides used for the control samples (In-EPID) were wrapped with gauze moistened with saline, and put inside a plastic bag, which was stored in a refrigerator at $5^{\circ} \mathrm{C}$. At each sampling time (at 24,48 and $72 \mathrm{~h}$ ), we recorded the osmolality and the $\mathrm{pH}$ of the different samples obtained from the cauda epididymis (In-EPID and Ex-EPID). Tubes with semen were sealed with Parafilm and kept at $5^{\circ} \mathrm{C}$ in a refrigerator until sampling.

\subsection{Evaluation of sperm quality}

Immediately after collection, volume was recorded and sperm concentration was assessed using Bürker hemocytometer (Marienfeld GmbH, Marienfeld, Germany) and evaluating the information through CASA (Sperm Class Analyzer; Microptic, Barcelona, Spain). In experiment 1, osmolality was measured using a cryoscopic osmometer Osmomat-030 (Gonotec $\bigwedge^{\mathrm{TM}}$, Berlin, Germany) and the $\mathrm{pH}$ value was determined by a CG 837 pHmeter (Schott Instruments, Main, Germany).
Motility: the motility was analyzed out using a computer-assisted sperm analysis system (CASA) (Sperm Class Analyzer; Microptic, Barcelona, Spain). A 5- $\mu$ L drop was taken from each of the different sampling tubes (InEPID, Ex-EPID, D320, D370, D420), and placed in a Makler counting cell chamber (10 $\mu \mathrm{m}$ depth; Sefi Medical Instruments, Haifa, Israel). The sample was examined at $10 \times$ (negative phase contrast) in a microscope with a warmed stage $\left(38^{\circ} \mathrm{C}\right)$. The standard settings were set at 25 frames $/ \mathrm{s}$, $20-90 \mu \mathrm{m}^{2}$ for head area and VCL $>10 \mu \mathrm{m} / \mathrm{s}$ to classify a spermatozoon as motile. At least five fields or 200 spermatozoa were saved and analyzed afterwards. Reported parameters were curvilinear velocity (VCL, $\mu \mathrm{m} / \mathrm{s}$ ) and linearity (LIN, \%). Total motility (TM) was defined as the percentage of spermatozoa with $\mathrm{VCL}>10 \mu \mathrm{m} / \mathrm{s}$, and progressive motility (PM) was defined as the percentage of spermatozoa with $\mathrm{VCL}>25 \mu \mathrm{m} / \mathrm{s}$ and $\mathrm{STR}>80 \%$ (straightness, also provided by the system).

\subsection{Viability and acrosome status}

These parameters were assessed simultaneously using fluorescence probes and flow cytometry. Briefly, samples were diluted in PBS at $5 \times 10^{6}$ spermatozoa $/ \mathrm{mL}$ and incubated for $15 \mathrm{~min}$ with $24 \mu \mathrm{M}$ of propidium iodide (PI) and $1 \mu \mathrm{g} / \mathrm{mL}$ of PNA-FITC (peanut agglutinin). PI stains membrane-damaged spermatozoa red, whereas PNA-FITC stains the acrosome green if it is damaged or reacted. Thus, we obtained four different subpopulations: red (non-viable sperm, intact acrosoma), green (viable sperm, damaged acrosome) red and green (non-viable sperm, damaged acrosome) or not-stained (viable sperm, intact acrosome).

To evaluate sperm viability, the double stain SYBR14/PI was used (LIVE/DEAD Sperm Viability Kit: Invitrogen, Barcelona, Spain). Sperm samples were diluted with PBS down to $5 \times 10^{6}$ spermatozoa $/ \mathrm{ml}$, and incubated with $24 \mu \mathrm{M}$ PI And $1.5100 \mathrm{nM}$ SYBR-14. The tubes were kept at $37 \wedge^{\mathrm{C}}$ for $20 \mathrm{~min}$ in the dark. We detected three populations corresponding to live spermatozoa (green), moribund spermatozoa (red + green) and dead spermatozoa (red).

Evaluation of flow cytometer parameters was carried out using a FACScalibur flow cytometer (Becton Dicknson System, San Jose, CA, USA) equipped with standard optics and an argon-ion laser, tuned at $488 \mathrm{~nm}$, and running at $200 \mathrm{mV}$. Data corresponding to the red (FL-3 photodetector) and green (FL-1 photodetector) fluorescence of 10,000 spermatozoa were recorded.

\subsection{Statistical analysis}

Statistical analyses were carried out using the R statistical package (http://www.r-project.org). Data were fitted to linear mixed-effect models by maximizing the loglikelihood (ML method). Male was always included as random effect and time (covariate) and treatment (factor with levels: storage in the epididymis and in extender with different osmolalities) as fixed effects. Results are given as mean \pm SEM. 


\section{Results}

\subsection{Experiment 1: comparison of intra-epididymal} versus undiluted extra-epididymal conservation

\subsubsection{Osmolality and $\mathrm{pH}$ of epididymal samples}

The osmolality of the In-EPID sample increased with post-mortem time (Fig. 1). At $0 \mathrm{~h}$, osmolality was $365 \pm 6 \mathrm{mOsm} / \mathrm{kg}$, which increased to $375 \pm 8,403 \pm 10$ and $421 \pm 12$ at 24,48 and $72 \mathrm{~h}$, respectively $(P<0.0001)$. However, the Ex-EPID samples stored undiluted in a glass tube did not show any significant differences with post-mortem time $(365 \pm 5 \mathrm{mOsm} / \mathrm{kg}$ at $0 \mathrm{~h}$ and $369 \pm 6$ at $72 \mathrm{~h})$. Similarly, $\mathrm{pH}$ did not vary significantly in the In-EPID samples (6.29 at 6.40,) or in the undiluted Ex-EPID ones (6.34 at 6.48) (Fig. 1).

\subsubsection{Spermatozoa quality}

The results of this experiment are shown in Table 1. After $24 \mathrm{~h}$ post-mortem, the In-EPID samples yielded higher motility (TM, PM, VCL and LIN) than the Ex-EPID ones stored undiluted in a glass tube $(P<0.05)$. These differences were not observed at 48 and $72 \mathrm{~h}$. Linearity (LIN) among these storage methods at any time. The spermatozoa stored in the epididymis showed higher viability and lower damaged acrosomes, being significantly different to the samples stored in glass tubes at $48 \mathrm{~h}(P<0.05)$.

For the Ex-EPID sample, TM, PM and VCL decreased significantly at $24 \mathrm{~h}$ in comparison with the control, VIAB decreased at 48 h, and LIN at $72 \mathrm{~h}$; ACR increased significantly at $48 \mathrm{~h}$ in comparison with the control. In the In-EPID samples, TM decreased significantly at $48 \mathrm{~h}$, and PM, VCL and VIAB decreased only at $72 \mathrm{~h}$ in comparison with the control. LIN and ACR did not significantly differ in these samples.

\subsection{Experiment 2: effect of extender osmolality in diluted epididymal spermâtozoa}

The total motility of the spermatozoa in the diluted samples was higher than in the other treatments at $24 \mathrm{~h}$ (Fig. 2 ); thus, the TM of D370 was significantly higher than in the control sample stored in epididymis. There were no significant differences among extenders for other motility parameters at $24 \mathrm{~h}$. At $48 \mathrm{~h}$ post-mortem, only LIN was different among treatments, with the control samples being significantly higher $(54.3 \pm 3.5 \%)$ than D370 $(41.8 \pm 3.7 \%)$ and $\mathrm{D} 420(38.1 \pm 3.6 \%)$. At $72 \mathrm{~h}$ post-mortem, motility (TM, $\mathrm{PM}$ and VCL) in the samples stored in D320 extender was significantly higher than in the other extenders.

The time of post-mortem storage had no significant effect on TM and PM for D320 and control (epididymisstored) samples. However, the motility of the spermatozoa stored in D370 or D420 extender decreased significantly in time. The kinetics parameters VCL and LIN showed a reduction only in D370 and D420, being significantly lower at $72 \mathrm{~h}$.

At $24 \mathrm{~h}$, the proportion of damaged acrosomes has no differences, but sperm viability was considerably higher for epididymis-stored samples $(79.8 \pm 5.1 \%)$ than for the extended samples (between $37.7 \pm 3.9$ to D370 and
$48.6 \pm 6.0 \%$ to $\mathrm{D} 420$ ). At $48 \mathrm{~h}$ and $72 \mathrm{~h}$, the proportion of damaged acrosomes increased for the extended samples, D370 and D420 being significantly higher than the control samples. The viability of spermatozoa declined in the extended samples with increasing storage time.

\section{Discussion}

Two main conclusions can be extracted from our results. First, quality of ram epididymal sperm is kept storing the spermatozoa in the epididymis at $5^{\circ} \mathrm{C}$, at least for $48 \mathrm{~h}$. Second, an extender of $320 \mathrm{mOsm} / \mathrm{kg}$ can preserve the motility of sperm extracted of epididymides but damage to acrosomes is observed.

In this study, we observed that the osmolality of freshly obtained samples, but not the $\mathrm{pH}$, increased in successive sampling times. Therefore, extracting the sample as soon as possible and storing it, could prevent these deleterious changes. Previously Martinez-Pastor et al. (2005b) observed that the osmolality and $\mathrm{pH}$ of the semen samples obtained from the epididymides of red deer and roe deer was increased with time post-mortem. Moreover, while collecting the sample from the epididymis, tissue, blood and other fluids can be mixed with the spermatozoa, decreasing their quality (Martinez-Pastor et al., 2006a). This suggest that the presence of tissue debris resulting from the collection of semen may speed up the process of deterioration of stored cells, although this process is equalized after $48 \mathrm{~h}$ in our test.

We observed in epidydimal storage a sustained decrease of motility at $48 \mathrm{~h}$ and $72 \mathrm{~h}$ and a reduction in cell viability at $72 \mathrm{~h}$. Others authors have observed that motility of spermatozoa was adversely affected by post-mortem storage in the epididymis (ram: Kaabi et al., 2003; red deer: Martinez-Pastor et al., 2005c; dog: Yu and Leibo, 2002). However, unlike what was observed in our study, several authors conclude that post-mortem storage does not affect sperm membrane integrity (red deer: Soler et al., 2003b and Martinez-Pastor et al., 2005c; dog: Yu and Leibo, 2002).

The loss of epididymal sperm quality may be related to the fertilizing capacity of sperm. A loss of fertilizing ability of epididymal spermatozoa with post-mortem time has been demonstrated in a few studies. Thus, Kaabi et al. (2003) showed that the in vitro fertilizing ability of epididymal spermatozoa was similar at $2 \mathrm{~h}(53 \%)$ and $24 \mathrm{~h}(45 \%)$ post-mortem, but decreased significantly at $48 \mathrm{~h}$ postmortem (38\%). However, other authors have observed that the fertilizing ability of epididymal spermatozoa decreased quickly with post-mortem time (red deer: Soler and Garde, 2003; mice: Songsasen et al., 1998; mouse: Sankai et al., 2001).

The extension of spermatozoa in a buffered medium could prevent some negative effects after collection, diluting unwanted fluids such as blood or interstitial fluid. In fact, the diluted spermatozoa showed better motility at $24 \mathrm{~h}$ post-mortem than the samples stored in the epididymis. Medium osmolality is crucial for the performance of spermatozoa (Yeung et al., 2006), and therefore we expected hyperosmotic media (370 or $420 \mathrm{mOsm} / \mathrm{kg}$ ) to be more appropriate for storing ram epididymal spermatozoa (with a mean osmolality of $365 \mathrm{mOsm} / \mathrm{kg}$ in our 

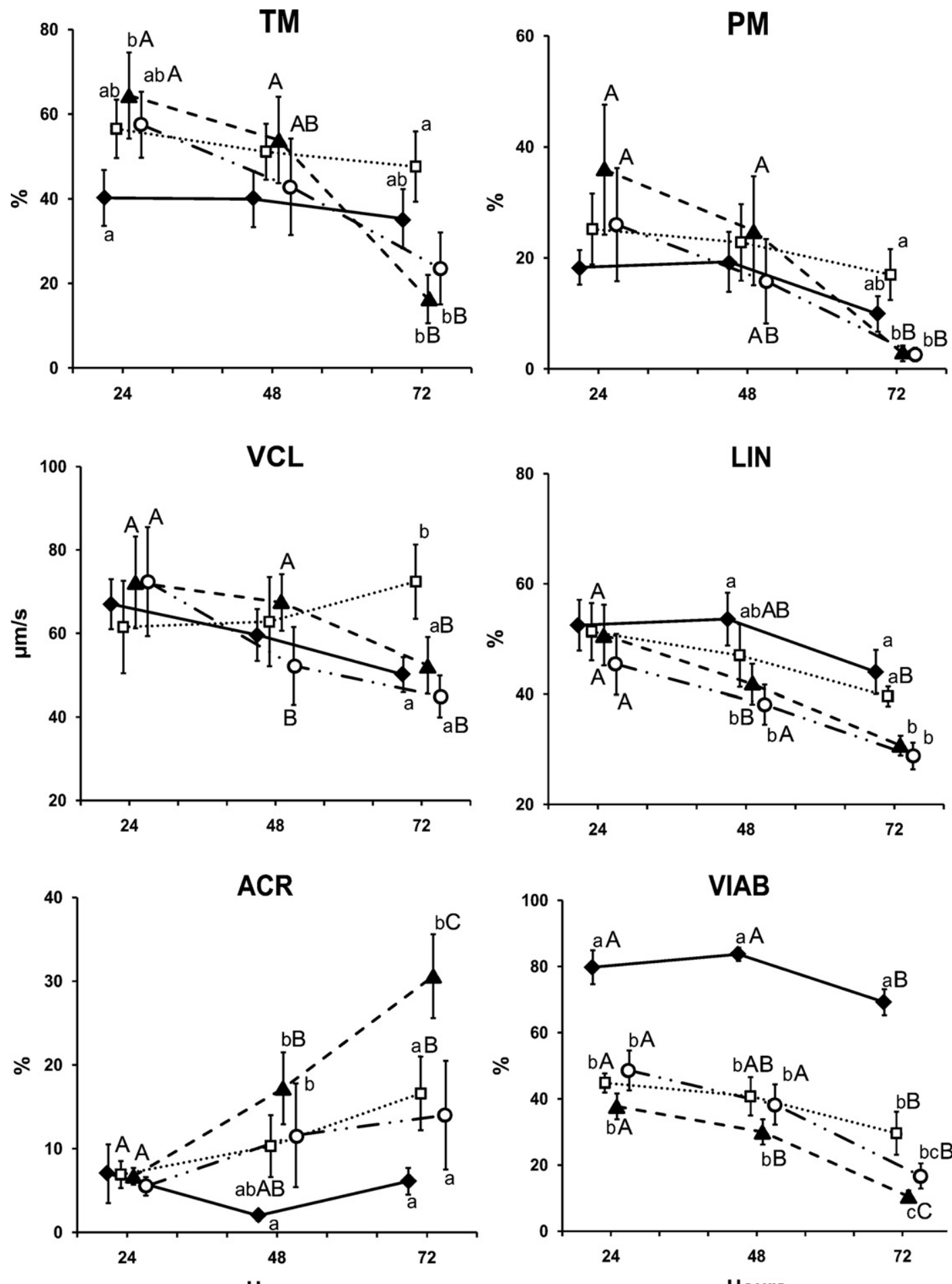

Hours

Hours

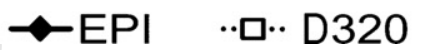

- $\Delta-$ D370

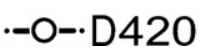

Fig. 2. Effects of extenders (D320, D370 or D420) on epididymal sperm quality stored at $5^{\circ} \mathrm{C}$ for 24 and 48 and $72 \mathrm{~h}$ (mean \pm SEM), applying semen from the cauda epididymis (In-EPID) as control. TM: total motility; PM: progressive motility; VCL: curvilinear velocity; LIN: linearity index; ACR: damaged acrosome; VIAB: viability. ab: different letters îficate differences $(\hat{P}<0.05)$ between extenders for each time period $(24$ and 48 and $72 \mathrm{~h})$. AB. $\bigwedge_{\text {different }}$ letters indicate differences $(P<0.05)$ between storing periods $(24$ and 48 and $72 \mathrm{~h})$ for each extender. 
Table 1

Comparison of the two storage methods at $5{ }^{\circ} \mathrm{C}$ (Intra-epididymal -In.EPID-versus undiluted extra-epididymal -Ex-EPID-) during 24,48 or $72 \mathrm{~h}$ post-mortem in comparison with a control $(0 \mathrm{~h})$. Results are shown as mean $\pm \mathrm{SEM}$.

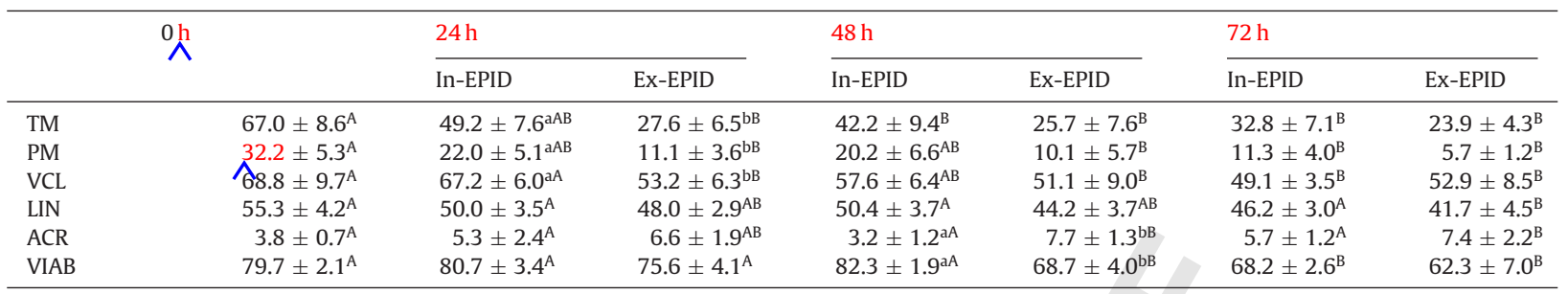

TM, total motility (\%); PM, \% progressive motility; VCL, curvilinear velocity ( $\mu \mathrm{m} / \mathrm{s}) ;$ LIN, linearity index (\%); ACR, damaged acrosomes (\%); VIAB, viability $\mathrm{ab}$, different letters in the same row indicate that the storage method (In-EPID and Ex-EPID) differs significantly within each storage time. $\mathrm{AB}$, different letters in the same row indicate that the values for storage time $(0,24,48$ and $72 \mathrm{~h})$ differ significantly within each storage method.

study) that a medium isotonic with epididymal fluid. For instance, Si et al. (2009) obtained higher fertility when collecting murine spermatozoa in hyperosmotic medium ( $415 \mathrm{mOsm} / \mathrm{kg}$, isoosmotic with the epididymal fluid) compared with spermatozoa collected in $290 \mathrm{mOsm} / \mathrm{kg}$ as assessed by IVF. Other authors have reported better sperm quality after freezing spermatozoa using moderately hyperosmotic extenders for epididymal spermatozoa (deer: Martinez-Pastor et al., 2006b and Fernandez-Santos et al., 2007; bear: Anel et al., 2010). However, we have observed that D320 extender maintains motility better and induces less acrosomal damage than the hyperosmotic extenders at prolonged post-mortem times $(72 \mathrm{~h}$ ).

The epididymal spermatozoa incubated into a extender showed a higher degree of membrane and acrosomal damage than those stored into the epididymides. Moreover, the loss of sperm viability does not correspond to a reduction in motility at the same storage time and extender. These results suggest that sperm motility and viability are affected by different mechanisms during the cold storage of epididymides.

The ability of extenders to modify sperm membranes, especially when containing egg yolk or milk, has been described previously (Bergeron et al., 2007). Whîe conveying some advantages, storing the spermatozoa in extenders could be triggering changes in membranes or in the general physiology of spermatozoa, which might increase their vulnerability to osmotic stress. It is noteworthy that, in our study, epididymal spermatozoa extended in D370 showed the lower results for sperm viability and acrosomes status, but D420 yielded similar results than D320. This suggests that extender osmolality could ameliorate or worsen the osmotic vulnerability of spermatozoa and confirms that the osmolality appears to exert a complex effect, as stated by Fernandez-Santos et al. (2007). Therefore, the hypothesis that a slightly hyperosmotic extender could provide the best environment for epididymal ram spermatozoa seems to be disproved and we note that a medium hypotonic to caudal epididymal plasma (D320) might be the best option for the conservation of diluted epididymal spermatozoa in ram. This medium can reduce cellular swelling caused by hypo-osmotic stress when epididymal spermatozoa endure the freezing process.

In conclusion, storing the spermatozoa in the epididymis at $5{ }^{\circ} \mathrm{C}$ is a good strategy for maintaining sperm quality in ram, at least for $48 \mathrm{~h}$, and is a better option than extracting the sperm mass and keeping it undiluted. We have also shown that extracting the sperm mass and diluting it in an extender of $320 \mathrm{mOsm} / \mathrm{kg}$ can preserve sperm motility at least as well as maintaining it in the epididymis. Nevertheless, the reduction of viability and damage to acrosomes in this extender must be analyzed and remediated improving the extender composition.

\section{Acknowledgements}

This work was supported in part by INIA (RZ200700011-00-00). The authors thank María Mata, Manuel Rodríguez, and Susana Gomes y Leticia Ordás for their help in the acquisition and analysis of the samples.

\section{References}

An, T.Z., Wada, S., Edashige, K., Sakurai, T., Kasai, M., 1999. Viable spermatozoa can be recovered from refrigerated mice up to 7 days after death. Cryobiology 38, 27-34.

Anel, L., Gomes-Alves, S., Alvarez, M., Borragan, S., Anel, E., Nicolas, M. Martinez-Pastor, F., de Paz, P., 2010. Effect of basic factors of extender composition on post-thawing quality of brown bear electroejaculated spermatozoa. Theriogenology 74, 643-651.

Bergeron, A., Brindle, Y., Blondin, P., Manjunath, P., 2007. Milk caseins decrease the binding of the major bovine seminal plasma proteins to sperm and prevent lipid loss from the sperm membrane during sperm storage. Biol. Reprod. 77, 120-126.

Canali, G., 2006. Common agricultural policy reform and its effects on sheep and goat market and rare breeds conservation. Small Rumin. Res. 62, 207-213.

Fernandez-Santos, M.R., Martinez-Pastor, F., Garcia-Macias, V., Esteso, M.C., Soler, A.J., de Paz, P., Anel, L., Garde, J.J., 2007. Extender osmolality and sugar supplementation exert a complex effect on the cryopreservation of Iberian red deer (Cervus elaphus hispanicus) epididymal spermatozoa. Theriogenology 67, 738-753.

Fernandez-Santos, M.R., Dominguez-Rebolledo, A.E., Esteso, M.C., Garde, J.J., Martinez-Pastor, F., 2009. Refrigerated storage of red deer epididymal spermatozoa in the epididymis, dîted and with vitamin $C$ supplementation. Reprod. Domest. Anim. 44, 212-220.

Ganan, N., Gomendio, M., Roldan, E.R., \$09. Effect of storage of domestic cat (Felis catus) epididymides at 5 degrees $C$ on sperm quality and cryopreservation. Theriogenology 72, 1268-1277.

Hishinuma, M., Suzuki, K., Sekine, J., 2003. Recovery and cryopreservation of sika deer (Cervus nippon) spermatozoa from epididymides stored at 4 degrees C. TherPogenology 59, 813-820.

Kaabi, M., Paz, P., Alvarez, M., Anel, E., Boixo, J.C., Rouissi, H., Herraez, P. Anel, L., 2003. Effect of epididymis handling conditions on the quality of ram spermatozoa recovered post-mortem. Theriogenology 60 , 1249-1259.

Kikuchi, K., Nagai, T., Kashiwazaki, N., Ikeda, H., Noguchi, J., Shimada, A., Soloy, E., Kaneko, H., 1998. Cryopreservation and ensuing in vitro fer- 
tilization ability of boar spermatozoa from epididymides stored at 4 degrees C. Theriogenology 50, 615-623.

Kishikawa, H., Tateno, H., Yanagimachi, R., 1999. Fertility of mouse spermatozoa retrieved from cadavers and maintained at 4 degrees $\mathrm{C}$. J. Reprod. Fertil. 116, 217-222.

Martinez-Pastor, F., Diaz-Corujo, A.R., Anel, E., Herraez, P., Anel, L., de Paz, P., 2005a. Post mortem time and season alter subpopulation characteristics of Iberian red deer epididymal sperm. Theriogenology 64 , 958-974.

Martinez-Pastor, F., Guerra, C., Kaabi, M., Diaz, A.R., Anel, E., Herraez, P., de Paz, P., Anel, L., 2005. Decay of sperm obtained from epididymes of wild ruminants depending on postmortem time. Theriogenology 63 , 24-40.

Martinez-Pastor, F., Guerra, C., Kaabi, M., Garcia-Macias, V., de Paz, P., Alvarez, M., Herraez, P., Anel, L., 2005c. Season effect on genitalia and epididymal sperm from Iberian red deer, roe deer and Cantabrian chamois. Theriogenology 63, 1857-1875.

Martinez-Pastor, F., Garcia-Macias, V., Alvarez, M., Chamorro, C., Herraez, P., de Paz, P., Anel, L., 2006a. Comparison of two methods for obtaining spermatozoa from the cauda epididymis of Iberian red deer. Theriogenology 65, 471-485.

Martinez-Pastor, F., Martinez, F., Garcia-Macias, V., Esteso, M.C., Anel, E., Fernandez-Santos, M.R., Soler, A.J., de Paz, P., Garde, J., Anel, L., 2006. A pilot study on post-thawing quality of Iberian red deer spermatozoa (epididymal and electroejaculated) depending on glycerol concentration and extender osmolality. Theriogenology 66, 1165-1172.

Martins, C.F., Driessen, K., Costa, P.M., Carvalho-Neto, J.O., de Sousa, R.V., Rumpf, R., Dode, M.N., 2009. Recovery, cryopreservation and fertilization potential of bovine spermatozoa obtained from epididymides stored at 5 degrees $\mathrm{C}$ by different periods of time. Anim. Reprod. Sci.
$116,50-57$.
Sankai, T., Tsuchiya, H., Ogonuki, N., 2001. Short-term nonfrozen storage of mouse epididymal spermatozoa. Theriogenology 55, 1759-1768.

Saragusty, J., Gacitua, H., King, R., Arav, A., 2006. Post-mortem semen cryopreservation and characterization in two different endangered gazelle species (Gazella gazella and Gazella dorcas) and one subspecies (Gazella gazelle acaiae). Theriogenology 66, 775-784.

Si, W., Men, H., Benson, J.D., Critser, J.K., 2009. Osmotic characteristics and fertility of murine spermatozoa collected in different solutions. Reproduction 137, 215-223.

Soler, A.J., Garde, J.J., 2003. Relationship between the characteristics of epididymal red deer spermatozoa and penetrability into zona-free hamster ova. J. Androl. 24, 393-400.

Soler, A.J., Garcia, A.J., Fernandez-Santos, M.R., Esteso, M.C., Garde, J.J., 2003a. Effects of thawing procedure on postthawed in vitro viability and in vivo fertility of red deer epididymal spermatozoa cryopre-
served at -196 degrees C. J. Androl. 24, 746-756.

Soler, A.J., Perez-Guzman, M.D., Garde, J.J., 2003b. Storage of red deer epididymides for four days at 5 degrees C: effects on sperm motility, viability, and morphological integrity. J. Exp. Zool. A: Comp. Exp. Biol. 295, 188-199.

Songsasen, N., Tong, J., Leibo, S.P., 1998. Birth of live mice derived by in vitro fertilization with spermatozoa retrieved up to twenty-four hours after death. .. Exp. Zool. 280, 189-196.

Yeung, C.H., Barfield, J.P., Cooper, T.G., 2006. Physiological volume regulation by spermatozoa. Mol. Cell. Endocrinol. 250, 98-105.

Yu, I., Leibo, S.P., 2002. Recovery of motile, membrane-intact spermatozoa from canine epididymides stored for 8 days at 4 degrees $C$. Theriogenology 57, 1179-1190. 